\title{
Practical Research of College Students' Innovation and Entrepreneurship Project for Food Major Based on OBE Concept
}

\author{
Di Yao ${ }^{1, *}$, Liyuan Zhang ${ }^{2}$, Chunzhi Zhang ${ }^{3}$ \\ College of Food, Heilongjiang Bayi Agricultural University, Daqing, Heilongjiang, 163319,China \\ *corresponding author
}

Keywords: College students' innovation and entrepreneurship project, Food Major, OBE Concept

\begin{abstract}
The efficient implementation of college students' innovation and entrepreneurship projects is conducive to cultivate students' innovative ability. Combining the OBE concept with innovation and entrepreneurship projects of food major, the necessity, implementation strategies and practical achievements of reforming college students' innovation and entrepreneurship projects were discussed which can promote improvement of university students' innovative ability and provide references for the cultivation of innovative talents.
\end{abstract}

\section{The Necessity of Reforming the Innovation and Entrepreneurship Project of Food College Students}

Innovation is power source for prosperity of a country and is the unique way to strengthen the country and the people. Driving innovation has become the preferred strategy for economic and social development in many countries and regions. However, the main body of innovation is talents. As an important base for the cultivation of talents, the universities shouldered the historical task of cultivating innovative talents. Strengthening the cultivation of innovative talents and improving the innovative ability of college students are becoming the core of higher education reform, and it is also a major issue that must be resolved in higher education. College students' innovation and entrepreneurship projects are conducive to cultivate students' innovative ability [1]. In recent years, more than $90 \%$ of universities in our country have actively launched innovation and entrepreneurship projects, but their practice models are still in exploration stage.

OBE is a outcome-oriented education [2]. OBE concepts and methods are considered as an effective method to pursue excellence in education. According to the "student-centric, outcome-oriented" specific implementation strategy of reforming university students' innovation and entrepreneurship projects, combining the OBE concept with the teaching activities of innovation and entrepreneurship projects, exploring the practice model of innovation and entrepreneurship projects is conducive to promote the innovative ability of college students and provide reference for training innovative talents. 


\subsection{Orientation of Training Objectives for Food Major}

Food industry is closely related to people's daily life. It is called "ever-rising sunrise industry". With the strategic adjustment of China's agricultural industry and development of the food industry, the food industry has proposed the new requirements for knowledge structure and innovative ability of talents [3]. In order to meet the needs of the society for food innovative talents, the training plan for food major must first resolve the problem location of the training goals. The requirements for the cultivation of innovation capabilities must be reflected in the location. At present, food major of our college implements "large-scale training". The training goal in the "large-scale" plan is to train students to engage in design, production, management, new technology research, and new product development in the food field. Obviously, the orientation of training objectives involves in the cultivation of students' innovative ability, especially in new technology research and new product development. Innovation and entrepreneurship projects need apply the theory of food major to practice. Through the process of "theory guiding practice and practice nurturing theory", students can increase recognization of new professional technologies, new processes, new methods, and sublimate in practice to effectively promote the cultivation of college students' innovative ability.

\subsection{The Necessity of Reforming College Students' Innovation and Entrepreneurship Project}

College students' innovation and entrepreneurship projects are a good carrier to drive the cultivation of university students' innovative ability [4], but there are certain problems in implementation process, such as the random selection of the project, the disconnection from the social needs, the disconnection from the professional direction, and the training goals are not clear. There are obstacles in communication between members of the project team and teacher. The project team members do not make full use of the university's educational resources. In addition, the practical skills of students is poor, they lack of the cultivation process of transforming theoretical knowledge into practice [5]. The teaching goals focus on completing project tasks and insufficient attention to the elements of achieving teaching goals. Therefore, we try to carry out reform and exploration of university students' innovation and entrepreneurship projects through outcome-oriented education which enable college students to gain from innovation and entrepreneurship training project.

\section{Implementation Strategy of Reforming Innovation and Entrepreneurship Projects for University Students of Food Major Based on OBE Concept}

\subsection{The Connotation of OBE Education Concept}

According to OBE education concept, the starting point of teacher teaching is not what the teacher wants to teach, but is what ultimate goal needs to be achieved. For students, the ultimate goal is what they have learned and what they have achieved. The connotation of OBE education model mainly includes the following four aspects:

Firstly, students are able to achieve the expected learning goals. We can determine the direction to be achieved only with clear goals. For teachers, in the process of education, they must always keep in mind the final learning goals of each student, and make timely adjustments and teach students according to their expected goals.

Secondly, teachers should provide guidance and assistance to students. Because each student's goal is different, various setbacks and obstacle will be encountered in the process of achieving the goals, such as unsatisfactory experimental results and experimental equipment which is difficult to support. At this time, teachers and schools need to provide necessary guidance and assistance. Such 
as, the reasons for unsatisfactory experimental results should be analyzed, experimental protocols should be adjusted reasonably, experimental equipment should be purchased or leased.

Thirdly, when teachers guide students for innovation and entrepreneurship training, some challenging research topics should be formulated. On one hand, students' potential and enthusiasm should be stimulated, on the other hand, more knowledge and goals should be achieved.

Fourthly, using the expected goals as a starting point for project arrangement and program design, we carried out project research based on the arranged research plans and goals. Always regarding students as the core, teachers guided them to learn for achieving the ultimate goals.

\subsection{Implementation Strategy of University Students' Innovation and Entrepreneurship Projects Based on OBE Concept}

Student-oriented and outcome-oriented was permeated in the implementation process of university students' innovation and entrepreneurship projects. The students were encouraged to participate in the projects, they design independently project topics and determine research plans. In order to improve their creativity, the specific implementation process was established. Students need to attach importance to the project research process and focus on practice. Students' curiosity and exploration was enhanced constantly. Students engaged in project research, organize and implement data analysis and write summary reports independently. Meanwhile, teachers guide students to use the OBE theory to analyze the problems and find the internal contradictions of the problems, and design and verify the solution programs to the problems. The teachers should inspire the students and stimulate their innovative thinking and cultivate their creativity. At the same time, students should also use consciously OBE theory and innovation principles to think about problems and acquire own innovative research results.

\section{The achievements of reforming college students' innovation and entrepreneurship projects based on the OBE concept}

Taking the achievements of an OBE concept-based college students' innovation and entrepreneurship project as an example, the following points are summarized:

\subsection{Ability to Seek and Use Literature was Improved}

In the early stages of the project, most students were not able to search for literature and resources, for example library literature databases. Through guiding of literature seeking, students could quickly acquire useful literature and contribute to understand the project.

\subsection{Students' Practice and Data Analysis Ability was Improved}

At the beginning of the study, students were always fearful and worried about making mistakes, and needed constant guidance to complete experimental tasks. Along of the continuous exploration, most students gradually possess the ability to dare to implement, and be good at processing experimental data and analyzing experimental results.

\subsection{Students' Scientific Logical Thinking and Paper Writing Ability was Improved}

Although students have taken a course in writing scientific paper, but they often have problems such as patchwork, disregard of the paper's thinking, disorder of logical thinking, narrow academic vision, and disorder of paper format. Taking the result orientation as the starting point, a systematic 
and in-depth summary should be made at the conclusion period of the project. Through systematic guidance and training, students' scientific thinking and paper writing ability have been improved. Two students published academic papers as first authors in domestic core journals.

\subsection{Ability of Team Collaboration was Improved}

Students' innovation and entrepreneurship projects are presided by students. The students needs to ask the instructor, discuss with the team members, and communicate with classmates and friends. In the process, students' communication ability was enhanced. We discuss the implementation of the project on weekly meeting, supplement and change timely the experimental scheme, cooperate with each other, and improve the team collaboration ability, which is very meaningful for participating in the future work.

\subsection{Students' Interest in Learning and Enthusiasm for Scientific Research was Aroused}

According to OBE concept, taking the students as core, the training process of innovation and entrepreneurship project was designed considering needs of all students. Let students feel that the theoretical knowledge learned in the classroom can be applied in specific experimental operations, it stimulates the students' interest in learning. At the same time, students' creative thinking and rigorous scientific attitude is cultivated in the process.

\section{Prospect}

The college student's innovation and entrepreneurship project based on the OBE concept can cultivate students' active learning ability to a certain extent, transforme knowledge education into outcome education, turn closed classrooms into open classrooms, and simultaneously achieve the transformation of unified knowledge and action. The project based on the OBE concept not only enhanced university students' innovation awareness and entrepreneurial ability, but also allowed them to play a subjective initiative in the process, and can actively discover, think about and solve problems. However, the specific assessment and evaluation system for college students' innovation and entrepreneurship projects needs to be further explored. A good evaluation system can promote the smooth development of the project and improve the innovative ability of students. The cultivation of creativity can play an important role on promoting the overall ability and comprehensive quality of students.

\section{Acknowledgment}

This work was supported by Research Project of Higher Education Teaching Reform in Heilongjiang Province (SJGY20180356) and Educational Science Key Projects of 13th Five Year Plan in Heilongjiang Province (Grant No. GJB1319100).

\section{References}

[1] He, W., Lin, G. (2019) Case Study on Guidance and Practical Effect of Innovation and Entrepreneurship Training Program for College Students, Research and Practice of Innovation and Entrepreneurship. Research and Practice of Innovation and Entrepreneurship Theory, 20, 187-188.

[2] Zhao, L.Y., Jin, Z.Y., Wang, J. (2019) Exploration on Training Mode of Innovative \& Applied Talents Based on OBE Mode. Guangzhou Chemical Industry, 47(24), 186-188.

[3] Liu, X.X., Ma, S., Jin, X. (2019) Exploration on Project Management Reform of Innovation and Entrepreneurship Training Plan for Food Major College Students Based on OBE Concept. Food and Fermentation Sciences \& Technology, 55(3), 127-131. 
[4] Li, H.Z., Peng, J.S., Rong, D.S. (2020) Research on the Training of Electrical Innovation Entrepreneurs Based on the Idea of OBE, Education Teaching Forum, 7, 285-287.

[5] Han, J.Y., Zhang, M.G. (2020) Research on teaching mode of innovation and entrepreneurship project based on OBE idea, Experimental Technology and Management, 37(2), 209-211. 